It's too early — and may never be possible — to credit Canadian legislation with having a clear impact on the number of medical-legal cases, says Dr. William Tucker, president of the protective association.

But expressions of sympathy can improve relations, he adds. "Families feel better if there is an acknowledgement that there has been an adverse event" and, after expressing regret and sympathy, it may be easier for a physician to carry on the therapeutic relationship.

Canadian apology legislation is broader than legislation in some Australian and US states where laws deal only with "expressions of regret" and stop short of addressing the issue of apology, says Windwick.

In August, the Canadian Medical Association and its provincial and territorial counterparts voted to jointly lobby governments for appropriate apology legislation in all Canadian jurisdictions. - Ann Silversides, CMAJ

\section{WHO report}

Countries must focus on primary care to address the growing gap between the world's rich and poor in health care access, costs and outcomes, the World Health Organization (WHO) says in its annual report on world health.

"The world health report sets out a better way to manage and deliver health care," said WHO Director-General Dr. Margaret Chan at the report's Oct. 14 launch in Almaty, Kazakhstan. "Primary care is a people-centred approach to health that makes prevention as important as cure."

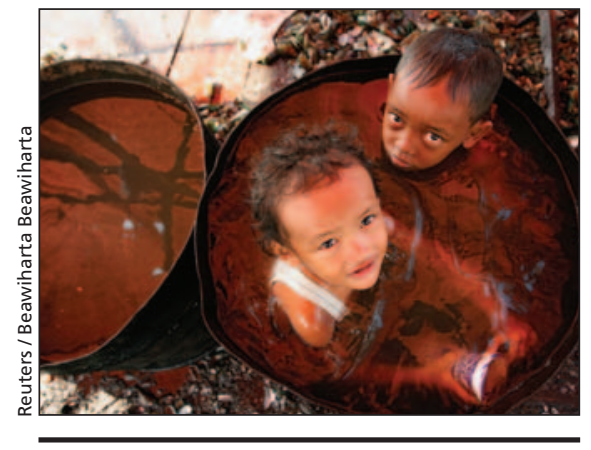

The 2008 world health report says health inequities among nations are growing.
The report, Primary Health Care: Now More Than Ever, asserts that many nations view health care primarily as the delivery of biomedical interventions and largely ignore the value of effective prevention. The WHO claims this is why health care inequalities between and within nations are greater today than they were 30 years ago.

According to the report, people in the richest countries can expect to live 40 years longer than people in the poor- est countries, where governments spend up to 300 times less per person on health care. The WHO claims the gap in access to care is greatest in areas that regard health care as a commodity for generating profit. Another problem, the report claims, is that health care organizations in many countries tend to focus too much on individual diseases. Roger Collier, CMAJ

DOI:10.1503/cmaj.081677

\title{
National health human resources plan "a hard sell"
}

$\mathrm{R}$ amping up the number of medical school spots without developing a national health human resources plan could perpetuate the boom-and-bust cycle of the past few decades, says the president of the Association of Faculties of Medicine of Canada.

Simply hiking enrolment doesn't answer vital questions such as how to integrate doctors into team-based models of care or determine the appropriate scope of practice for health care workers in order to avoid overlap, says Dr. Nick Busing. But the federal leadership and support that is needed to develop a central planning mechanism is missing and developing a national plan "is a hard sell with this government."

"For them, health care is a provincial issue, but I would argue they should be leading the discussion."

Busing says medical school teaching resources are already strained, because of recent increases in the number of students and the shift to regional campuses.

First-year medical school enrolment spots increased by $63 \%$ in the decade ending in 2007-08 (to 2569 spots from 1577), and the satellite campus approach has meant a "bringing on board a whole new cohort of teachers."

About one-third of Canada's doctors already assume clinical teaching roles, but many lack formal training in pedagogy, and support and remuneration are variable, according to the association. Busing notes that none of the federal money transferred to provinces under the 2003 First Ministers' Accord on
Health Care Renewal has been earmarked for education.

What's needed is a mechanism to monitor the number of trainees, conduct research and "provide careful recommendations to help us plan our health human resources into the future."

The European Union is working to harmonize its health human resource planning and Australia, where health care responsibility lies at the state level, has taken a federal approach to planning, Busing notes.

In the early 1990s, medical school spots were cut without adequate analysis of issues such as the aging physician workforce, shifting morbidity patterns and changes in doctors' roles.

"I'm concerned that now we are ramping up again, but we still haven't done the analysis. We are reacting to legitimate needs, but again we aren't doing this in an evidence-based way," says Busing.

The need for a pan-Canadian approach to health human resource planning was emphasized in the final report of Task Force Two, the multi-stakeholder 2006 group that examined physician human resource strategy for Canada (CMAJ 2006;174[13]:1827-8).

"Jurisdiction-specific policies are appropriate where systems of health care are completely separate. However, Canadian health care systems have a high level of inter-dependency," the report states. - Ann Silversides, CMAJ

DOI:10.1503/cmaj.081710 